\title{
DIFFERENCE OF COMPOSITION OPERATORS ON THE BERGMAN SPACES OVER THE BALL
}

\author{
MaOfa WANG AND Xin GuO
}

\begin{abstract}
This paper characterizes the compactness of a linear combination of three composition operators on $A_{\alpha}^{p}\left(\mathbb{B}^{N}\right)$, the weighted Bergman space over the unit ball $\mathbb{B}^{N}$ in $\mathbb{C}^{N}$. In this setting, we show that there is no cancellation property for the compactness of double difference of composition operators, which extends Koo-Wang's results over the unit disk in [13]. In addition, we investigate the compactness and essential norm estimate of the differences of weighted composition operators between weighted Bergman spaces.
\end{abstract}

Mathematics subject classification (2010): Primary 47B33, Secondary 32A35, 32A36.

Keywords and phrases: Bergman space, weighted composition operator, compact difference.

\section{REFERENCES}

[1] H. Cho, B. ChoE AND H. Koo, Linear combinations of composition operators on the Fock-Sobolev spaces, Potential Anal. 41, 4 (2014), 1223-1246.

[2] B. ChOE, H. KoO AND I. PARK, Compact differences of composition operators over polydisks, Integral Equations Operator Theory 73, 1 (2012), 57-91.

[3] B. Choe, H. Koo And I. Park, Compact differences of composition operators on the Bergman spaces over the ball, Potential Anal. 40, 1 (2014), 81-102.

[4] B. Chot, H. Koo, M. WANG ANd J. YAnG, Compact linear combinations of composition operators induced by linear fractional maps, Math. Z. 280, 3-4 (2015), 807-824.

[5] B. Chot, H. Koo AND M. WANG, Compact double differences of composition operators on the Bergman spaces, J. Funct. Anal. 272, 6 (2017), 2273-2307.

[6] C. Cowen AND B. MACCluer, Composition operators on spaces of analytic functions, CRC Press, New York, 1995.

[7] X. Guo, M. WANG, Difference of weighted composition operators on the space of Cauchy integral transforms, Taiwanese J. Math. 22, 6 (2018), 1435-1450.

[8] K. Heller, B. MacCluer AND P. WeIR, Compact differences of composition operators in several variables, Integral Equations Operator Theory 69, 2 (2011), 247-268.

[9] T. Hosokawa AND S. OHno, Differences of composition oprtators on the Bloch spaces, J. Operator Theory 57, 2 (2007), 229-242.

[10] L. JiAng AND C. OUYANG, Compact differences of composition operators on holomorphic function spaces in the unit ball, Acta Math. Sci. Ser. B Engl. Ed. 31, 5 (2011), 1679-1693.

[11] Z. JIANG AND S. STEvić, Compact differences of weighted composition operators from weighted Bergman spaces to weighted-type spaces, Appl. Math. Comput. 217, 7 (2010), 3522-3530.

[12] H. Koo AND M. WANG, Joint Carleson measure and the difference of composition operatos on $A_{\alpha}^{p}\left(\mathbb{B}_{n}\right)$, J. Math. Anal. Appl. 419, 2 (2014), 1119-1142.

[13] H. Koo And M. WANG, Cancellation properties of composition operators on Bergman spaces, J. Math. Anal. Appl. 432, 2 (2015), 1174-1182.

[14] T. KRIETE AND J. MOORHOUSE, Linear relations in the Calkin algebra for composition operators, Trans. Amer. Math. Soc. 359, 6 (2007), 2915-2944.

[15] J. Moorhouse, Compact difference of composition operators, J. Funct. Anal. 219, 1 (2005), 70-92.

[16] W. Rudin, Function theory in the unit ball of $C^{n}$, Springer-Verlag, New York-Berlin, 1980. 
[17] E. SAUKKO, Difference of composition operators between standard weighted Bergman spaces, J. Math. Anal. Appl. 381, 2 (2011), 789-798.

[18] E. SAUKKO, An application of atomic decomposition in Bergman spaces to the study of differences of composition operators, J. Funct. Anal. 262, 9 (2012), 3872-3890.

[19] J. SHARPIRO, Composition operators and classical function theory, Springer-Verlag, New York, 1993.

[20] S. STEVIĆ AND Z. JIANG, Compactness of the difference of weighted composition operators from weighted Bergman spaces to weighted-type spaces on the unit ball, Taiwanese J. Math. 15, 6 (2011), $2647-2665$.

[21] M. WANG, X. GuO, Difference of generalized integration operators on the space of Cauchy transforms, Complex Var. Elliptic Equ., https://doi.org/10.1080/17476933.2018.1450394.

[22] M. WANG, X. GuO, Difference of differentiation composition operators on the fractional Cauchy transforms spaces, Numer. Funct. Anal. Optim., https://doi.org/10.1080/01630563.2018 .1477798 .

[23] M. WANG AND C. PANG, Compact double differences of composition operators over the half-plane, Complex Anal. Oper. Theory 12, 1 (2018), 261-292.

[24] K. ZHU, Spaces of holomorphic functions in the unit ball, Springer-Verlag, New York, 2005.

[25] K. ZHU, Compact compositions operators on Bergman spaces of the unit ball, Houston J. Math. 33, 1 (2007), 273-283. 